\title{
Acute effect of fructose on postprandial lipaemia in diabetic and non-diabetic subjects
}

\author{
Arefaine Abraha ${ }^{1}$, Sandy M. Humphreys ${ }^{2}$, Mo L. Clark ${ }^{2}$, David R. Matthews ${ }^{3}$ and Keith N. Frayn ${ }^{2} *$ \\ ${ }^{1}$ Department of Chemical Pathology, Burnley General Hospital, Casterton Avenue, Burnley BB10 2PQ, UK \\ ${ }^{2}$ Oxford Lipid Metabolism Group, Radcliffe Infirmary, Woodstock Road, Oxford OX2 6HE, UK \\ ${ }^{3}$ Oxford Centre for Diabetes and Endocrinology, Radcliffe Infirmary, Woodstock Road, Oxford OX2 6HE, UK
}

(Received 3 December 1997 - Accepted 19 February 1998)

\begin{abstract}
We investigated whether the potentiation of postprandial lipaemia by fructose occurs in both nondiabetic subjects and those with non-insulin-dependent diabetes mellitus. Six non-diabetic and six diabetic subjects were studied on two occasions. They were given a meal containing $1 \mathrm{~g}$ fat $/ \mathrm{kg}$ body weight with, on one occasion, $0.75 \mathrm{~g}$ fructose $/ \mathrm{kg}$ body weight, on the other occasion $0.75 \mathrm{~g} \mathrm{starch} / \mathrm{kg}$ body weight. In both groups, plasma glucose and insulin concentrations rose more after starch than after fructose. At $1-2 \mathrm{~h}$ after the meal, plasma non-esterified fatty acid concentrations were suppressed more after fructose than after starch, but later they rose more after fructose than after starch. Plasma triacylglycerol concentrations rose more slowly after fructose, but were considerably higher than those after starch from $4-6 \mathrm{~h}$ after the meal. There were no differences in post-heparin plasma lipoprotein lipase (EC 3.1.1.34) activity at the end of the test. The potentiation of postprandial lipaemia by fructose was positively related to the fasting plasma insulin concentration, suggesting that insulin-resistant subjects are more prone to this effect. We conclude that the potentiation of postprandial lipaemia by fructose is seen in both diabetic and non-diabetic subjects. Our results suggest that alterations in the dynamics of plasma non-esterified fatty acids might underlie the effects of fructose on triacylglycerol metabolism.
\end{abstract}

Fructose: Postprandial lipaemia: Non-insulin-dependent diabetes mellitus

It has long been recognized that high-carbohydrate diets may lead to an elevation of the plasma triacylglycerol (TAG) concentration (Ruderman et al. 1971). The role played by specific sugars such as fructose and sucrose, or by starch, has been more controversial (MacDonald \& Braithwaite, 1964). There appears to be a more marked effect of sugars or carbohydrate on postprandial lipaemia than on fasting lipid levels (Hayford et al. 1979). Many of the studies showing a relationship between the consumption of sugars such as sucrose or fructose and plasma TAG concentration have used test meals that were part of the current diet, making it impossible to distinguish acute effects of these sugars from their chronic effects. Recently, two reports demonstrated an exaggerated postprandial lipaemia in response to fructose added to a single test meal (Grant et al. 1994; Jeppesen et al. 1995). In neither of these studies was there control of the total carbohydrate content of the test meal, raising the question of how specific the effect is to dietary fructose.

Since the metabolism of fructose is largely insulinindependent, the replacement of glucose by fructose as a sweetener for people with diabetes has long been an attractive proposal (Moorhouse \& Kark, 1957). However, because hypertriacylglycerolaemia may be a particularly important risk factor for macrovascular disease in diabetic subjects (Austin, 1989), the idea of replacing glucose by fructose in the diabetic diet is still a matter of concern. In marked contrast to the results in non-diabetic subjects, however, the TAG-raising effect of dietary fructose or sucrose is much less consistent in subjects with insulindependent diabetes mellitus and non-insulin-dependent diabetes mellitus (NIDDM; for review, see Frayn \& Kingman, 1995). It is not clear why this should be so.

The present study, therefore, was designed to investigate the acute effect of added fructose, compared with starch, on postprandial TAG concentrations in non-diabetic subjects, and to test whether this effect might be different in subjects with NIDDM. The results in non-diabetic subjects have been published in abstract form (Abraha et al. 1996).

\section{Materials and methods}

Subjects and experimental design

The study was approved by the Central Oxford Research 
Table 1. Biochemical characteristics of the subjects*

(Values are means and ranges for six subjects in each group)

\begin{tabular}{|c|c|c|c|c|}
\hline \multirow[b]{2}{*}{ Variable } & \multicolumn{2}{|c|}{ Non-diabetic subjects } & \multicolumn{2}{|c|}{ Diabetic subjects } \\
\hline & Mean & Range & Mean & Range \\
\hline $\begin{array}{l}\text { Plasma glucose }(\mathrm{mmol} / \mathrm{l}) \\
\text { Plasma triacylglycerol }(\mathrm{mmol} / \mathrm{l}) \\
\text { Plasma cholesterol }(\mathrm{mmol} / \mathrm{l}) \\
\text { HDL-cholesterol (mmol/l) }\end{array}$ & $\begin{array}{l}4 \cdot 7 \\
0 \cdot 79 \\
4 \cdot 82 \\
1 \cdot 14\end{array}$ & $\begin{array}{c}4 \cdot 3-5 \cdot 1 \\
0 \cdot 56-1 \cdot 08 \\
3 \cdot 50-8 \cdot 00 \\
0 \cdot 64-1 \cdot 57\end{array}$ & $\begin{array}{l}9 \cdot 6 \\
1 \cdot 55 \\
4 \cdot 60 \\
0 \cdot 87\end{array}$ & $\begin{array}{r}7 \cdot 4-11 \cdot 9 \\
0 \cdot 88-3 \cdot 28 \\
3 \cdot 90-5 \cdot 70 \\
0 \cdot 41-1 \cdot 35\end{array}$ \\
\hline
\end{tabular}

* Data are for samples taken after overnight fast.

Table 2. Composition of the test meals*

\begin{tabular}{|c|c|c|c|c|}
\hline & \multicolumn{2}{|c|}{ Starch meal } & \multicolumn{2}{|c|}{ Fructose meal } \\
\hline & g & $\mathrm{g} / \mathrm{kg}$ fat & $g$ & $\mathrm{~g} / \mathrm{kg}$ fat \\
\hline Carbohydrate & 51.6 & & $54 \cdot 2$ & \\
\hline $\begin{array}{l}\text { Fat } \\
\text { Saturated } \\
\text { Monounsaturated } \\
\text { Polyunsaturated } \\
\text { Cholesterol }\end{array}$ & 0.8 & $\begin{array}{r}61 \cdot 1 \\
57 \cdot 6 \\
35 \cdot 3 \\
7 \cdot 1\end{array}$ & $0 \cdot 8$ & $\begin{array}{r}59 \cdot 7 \\
58 \cdot 0 \\
35 \cdot 7 \\
6 \cdot 3\end{array}$ \\
\hline Protein & 31.7 & & $31 \cdot 7$ & \\
\hline
\end{tabular}

* To each meal was added $200 \mathrm{ml}$ low-energy lemon-flavoured drink.

Ethics Committee and all subjects gave their written informed consent. Six non-diabetic subjects and six patients with NIDDM were recruited. The non-diabetic subjects were three males and three females with a median age of 48 (range 30-61) years and a median BMI of 23.6 (range $17.6-26.3) \mathrm{kg} / \mathrm{m}^{2}$. The diabetic patients were four males and two females with a median age of 47 (range 43-54) years and a median BMI of $28 \cdot 2$ (range $23 \cdot 1-33$ ) $\mathrm{kg} / \mathrm{m}^{2}$. Some biochemical characteristics are listed on Table 1 . The subjects were not on any medication that would affect their lipid metabolism. All subjects had a normal blood pressure, and normal renal and thyroid function tests. Five of the diabetic subjects were on oral hypoglycaemic agents and one was on a controlled diet. Two of the female subjects were pre-menopausal and both parts of the experiment were carried out at the same phase of their cycle. One of the three post-menopausal women was on hormone-replacement therapy.

Subjects attended on two occasions after an overnight fast. A cannula was placed in a forearm vein and kept patent by flushing with saline $(9 \mathrm{~g} \mathrm{NaCl} / \mathrm{l})$. The subjects were given a test meal consisting of scrambled egg cooked in double cream and butter providing $1 \mathrm{~g}$ fat $/ \mathrm{kg}$ body weight. On one occasion this was given with fructose $(0.75 \mathrm{~g} / \mathrm{kg}$ body weight) dissolved in a lemon-flavoured low-energy drink, and on the second occasion starch $(0.75 \mathrm{~g} / \mathrm{kg}$ body weight) in the form of toasted bread, was substituted for the fructose. The composition of the test meals is given in Table 2. Blood samples were taken through the cannula before and after the test meals. Post-meal samples were taken every $15 \mathrm{~min}$ during the first hour, every 30 min during the second hour and hourly for the following $6 \mathrm{~h}$. After the $6 \mathrm{~h}$ sample, heparin (100 units/kg body weight) was given intravenously and a further blood sample was taken 15 min later for estimation of lipoprotein lipase (LPL) (EC 3.1.1.34) activity.

\section{Analytical methods}

Glucose concentrations were determined on whole blood immediately after collection using the HemoCue B-glucose microcuvette and photometer kit method (HemoCue A.B. S-26223 Angelholm, Sweden). Insulin concentrations were measured in plasma using the Pharmacia insulin RIA 100 kit (Pharmacia AB, Uppsala, Sweden). TAG concentrations in plasma were determined using the method of Humphreys et al. (1990) with correction for free glycerol, adapted to an IL Monarch Clinical Chemistry Analyser (Instrumentation Laboratories, Warrington, UK). The plasma non-esterified fatty acid (NEFA) concentration was measured using a commercial kit (Wako NEFA C kit; Alpha Laboratories Ltd., Eastleigh, Hampshire, UK) adapted for the IL Monarch Clinical Chemistry Analyser.

Post-heparin plasma LPL activity was determined by hydrolysis of ${ }^{3} \mathrm{H}$-labelled triolein in a glycerol-based emulsion (Nilsson-Ehle \& Schotz, 1976). Lipase activity in the presence of $1 \mathrm{~mol} \mathrm{NaCl} / \mathrm{l}$ (assumed due to hepatic lipase) was subtracted from total lipase activity. All samples from the non-diabetic group were analysed in a single batch and all those from the diabetic group in a different batch.

\section{Calculations and statistical methods}

Areas under curves for metabolites $v$. time were calculated using a trapezoidal method. Incremental areas under curves were calculated for the postprandial period by subtracting the mean baseline value extrapolated over the $360 \mathrm{~min}$ postprandial period. These were divided by the time-base (360 $\mathrm{min}$ ) to give time-averaged changes in the postprandial period. Differences between the meals (starch $v$. fructose) were tested using Wilcoxon's rank sum test. 
Table 3. Postprandial changes in plasma metabolites and insulin based on incremental areas under the curve* for diabetic and non-diabetic subjects after test meals containing starch or fructose $\dagger$

(Mean values with their standard errors for six subjects in each group)

\begin{tabular}{|c|c|c|c|c|c|}
\hline & \multicolumn{2}{|c|}{ Starch meal } & \multicolumn{2}{|c|}{ Fructose meal } & $\begin{array}{l}\text { Statistical significance of } \\
\text { difference between meals }\end{array}$ \\
\hline \multicolumn{6}{|l|}{ Non-diabetic subjects } \\
\hline Glucose $(\mathrm{mmol} / \mathrm{l})$ & 0.23 & 0.23 & 0.09 & $0 \cdot 10$ & 0.345 \\
\hline Non-esterified fatty acids $(\mu \mathrm{mol} / \mathrm{l})$ & $-33 \cdot 4$ & $55 \cdot 1$ & $-30 \cdot 2$ & $49 \cdot 0$ & 0.753 \\
\hline Insulin (mU/l) & $7 \cdot 01$ & $1 \cdot 32$ & 3.84 & $0 \cdot 42$ & 0.046 \\
\hline Glucose $(\mathrm{mmol} / \mathrm{l})$ & 2.59 & 0.66 & 0.01 & 0.48 & 0.027 \\
\hline Non-esterified fatty acids $(\mu \mathrm{mol} / \mathrm{l})$ & $-115 \cdot 1$ & $87 \cdot 8$ & $-126 \cdot 2$ & $53 \cdot 6$ & 0.917 \\
\hline Insulin (mU/I) & $17 \cdot 91$ & $8 \cdot 80$ & 8.86 & $3 \cdot 78$ & 0.046 \\
\hline
\end{tabular}

* Values are time-averaged change from baseline values, calculated as incremental area under the curve divided by time (min).

† For details of subjects and procedures, see pp. 170-171 and Tables 1 and 2.

Table 4. Post-heparin plasma lipoprotein lipase (EC 3.1.1.34) activity* for diabetic and non-diabetic subjects after test meals containing starch or fructose $\dagger$

(Mean values with their standard errors for six subjects in each group)

\begin{tabular}{|c|c|c|c|c|}
\hline & \multicolumn{2}{|c|}{ Starch mealł } & \multicolumn{2}{|c|}{ Fructose mealł } \\
\hline & Mean & SEM & Mean & SEM \\
\hline Non-diabetic subjects & $209 \cdot 8$ & $28 \cdot 2$ & $180 \cdot 4$ & $34 \cdot 9$ \\
\hline Diabetic subjects & $113 \cdot 1$ & $16 \cdot 0$ & $108 \cdot 3$ & $14 \cdot 4$ \\
\hline
\end{tabular}

* Values are for enzyme activity (nmol fatty acid released/min per ml plasma), measured at 375 min after the meal, 15 min after injection of heparin (100 units/kg body weight).

† For details of subjects and procedures, see p. 170 and Tables 1 and 2.

Plasma metabolite and insulin concentrations were analysed using repeated-measures ANOVA with time and meal type as within-subject factors and group (diabetic or non-diabetic) as a between-subject factor. Relationships between variables were analysed using Spearman's rank correlation coefficient. Statistical calculations were made using SPSS for Windows Release 7.0 (SPSS Inc., Chicago, IL, USA).

\section{Results}

\section{Blood glucose and plasma insulin concentrations}

In both groups, blood glucose concentrations started rising $15 \mathrm{~min}$ after the meals and reached a peak at approximately $30 \mathrm{~min}$ in the non-diabetic subjects and $60 \mathrm{~min}$ in the diabetic subjects. In both groups, blood glucose concentrations were higher after the starch meal than after the fructose meal at all times during the study period (Fig. 1). The plasma insulin response was much lower after the fructose meal than after the starch meal in both diabetic and nondiabetic subjects (Fig. 2).

\section{Plasma non-esterified fatty acid and triacylglycerol} concentrations and post-heparin lipoprotein lipase activity

Plasma NEFA concentrations are shown in Fig. 3. The concentration of plasma NEFA fell in both groups of subjects and after both meals for the first $60 \mathrm{~min}$ after the meal. The nadir was delayed by about $30 \mathrm{~min}$ in the diabetic subjects compared with the non-diabetic subjects. After the nadir, plasma NEFA concentration rose for the duration of the study. In both groups of subjects, the plasma NEFA concentration after the fructose meal was lower than that after the starch meal during the first 240 min of the study period. After this time the relationship between the meals and the plasma NEFA concentration was reversed, and plasma NEFA concentrations were higher after the fructose meal than after the starch meal in both groups.

The plasma TAG concentration started rising 15-30 min after the starch meal in both groups of subjects. After the fructose meal, however, the rise in plasma TAG concentration did not start until about 90 min after the meal (Fig. 4). Beyond $90 \mathrm{~min}$, the plasma TAG concentration rose much faster after the fructose meal than after the starch meal in both diabetic and non-diabetic subjects. As in the case of plasma NEFA concentrations, the reversal in plasma TAG concentration between the two meals took place about $180 \mathrm{~min}$ after the meals. In both diabetic and non-diabetic subjects, the postprandial incremental plasma TAG concentration was significantly higher (Table 3 ) after fructose than after starch.

Post-heparin plasma lipoprotein lipase activities (Table 4) showed no differences between the meals within either group of subjects. Although activities in the diabetic subjects appear to be lower than those in the nondiabetic subjects, this may reflect in part between-batch analytical variation. 


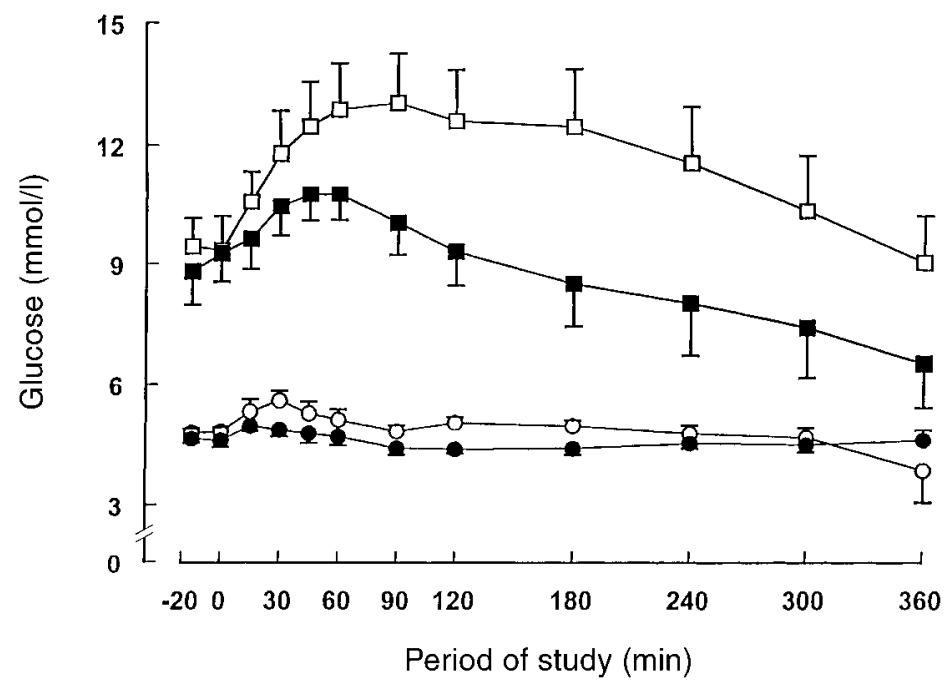

Fig. 1. Blood glucose concentrations of diabetic and non-diabetic subjects before and after test meals containing starch or fructose $(0.75 \mathrm{~g} / \mathrm{kg}$ body weight). ( $\square)$, Diabetic subjects after starch test meal; (ם), diabetic subjects after fructose test meal; $(O)$, non-diabetic subjects after starch test meal; $(\bullet)$, non-diabetic subjects after fructose test meal. Points represent mean values with their standard errors for six diabetic and six non-diabetic subjects. Repeatedmeasures ANOVA shows significant main effects of time $(P<0.001)$, meal type $(P=0.001)$ and group $(P=0.001)$, with significant meal $\times$ time $(P<0.001)$, group $\times$ time $(P<0.001)$ and meal $\times$ group $(P=0.013)$ interactions. For details of subjects and procedures, see p. 170 and Tables 1 and 2.

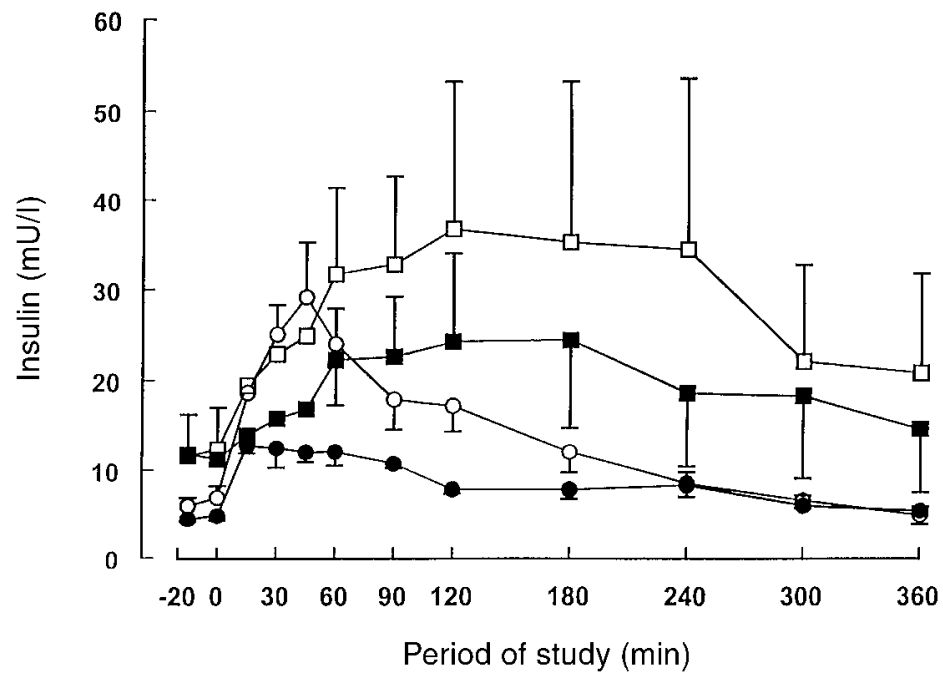

Fig. 2. Plasma insulin concentration of six diabetic and six non-diabetic subjects before and after test meals containing starch or fructose $(0.75 \mathrm{~g} / \mathrm{kg}$ body weight). ( $\square)$, Diabetic subjects after starch test meal; $(\mathbf{\square})$, diabetic subjects after fructose test meal; $(O)$, non-diabetic subjects after starch test meal; $(\bullet)$, non-diabetic subjects after fructose test meal. Points represent mean values with their standard errors for six diabetic and six non-diabetic subjects. Repeated-measures ANOVA shows significant main effects of time $(P<0.001)$ and meal type $(P=0.016)$, with significant meal $\times$ time $(P=0.011)$ and group $\times$ time $(P=0.007)$ interactions. For details of subjects and procedures, see pp. 170-171 and Tables 1 and 2.

\section{Relationships between plasma insulin and triacylglycerol concentrations}

The fasting plasma TAG concentration, over all twelve subjects, was significantly related to the fasting plasma insulin concentration (Spearman's rank correlation coefficient 0.71, $P=0.009$ ). The potentiation of postprandial lipaemia by fructose in each subject was expressed as the percentage increase in incremental area under curve for plasma TAG $v$. time after the fructose meal compared with the starch meal. The 'fructose effect' expressed in this way was significantly related to the fasting plasma insulin concentration (Spearman's rank correlation coefficient $0.69, P=0.013$; Fig. 5), but not to the fasting plasma TAG concentration $(P=0 \cdot 15)$. 


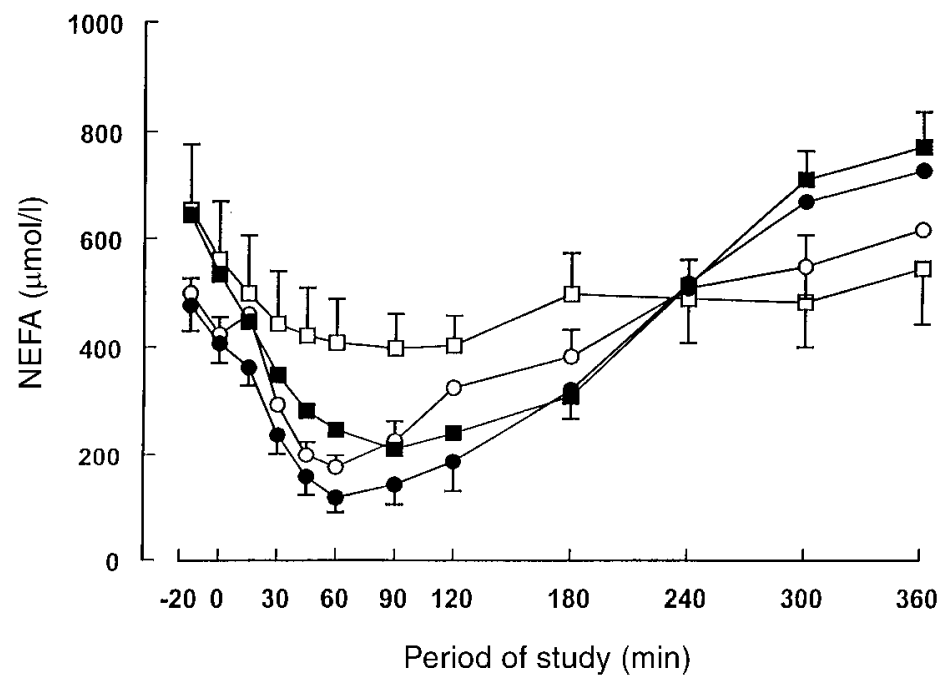

Fig. 3. Plasma non-esterified fatty acid (NEFA) concentrations of diabetic and non-diabetic subjects before and after test meals containing starch or fructose $(0.75 \mathrm{~g} / \mathrm{kg}$ body weight). ( $\square)$, Diabetic subjects after starch test meal; (ם), diabetic subjects after fructose test meal; $(O)$, non-diabetic subjects after starch test meal; $(\bullet)$, non-diabetic subjects after fructose test meal. Points represent mean values with their standard errors for six diabetic and six non-diabetic subjects. Repeated-measures ANOVA shows significant main effect of time $(P<0.001)$, with significant meal $\times$ time $(P<0.001)$, group $\times$ time $(P=0.05)$ and meal $\times$ group $(P=0.017)$ interactions. For details of subjects and procedures, see p. 170 and Tables 1 and 2 .

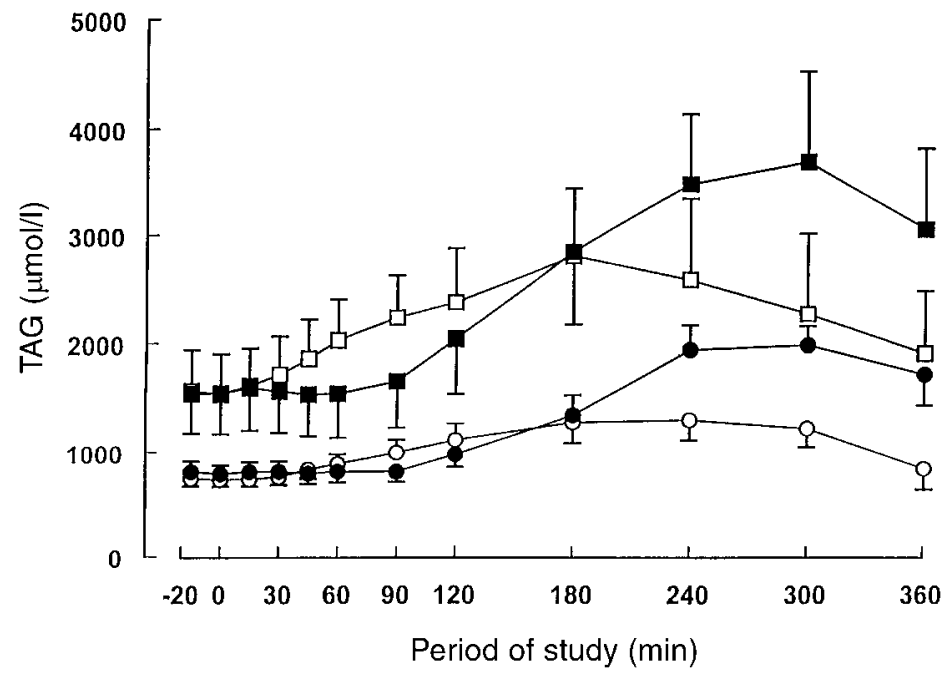

Fig. 4. Plasma triacylglycerol (TAG) concentrations of six diabetic and six non-diabetic subjects before and after test meals containing starch or fructose $(0.75 \mathrm{~g} / \mathrm{kg}$ body weight).

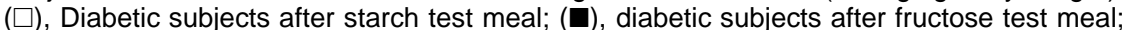
$(\bigcirc)$, non-diabetic subjects after starch test meal; $(\bullet)$, non-diabetic subjects after fructose test meal. Points represent mean values with their standard errors for six diabetic and six non-diabetic subjects. Repeated-measures ANOVA shows significant main effect of time $(P<0.001)$, with significant meal $\times$ time $(P<0.001)$ interaction. For details of subjects and procedures, see p. 170 and Tables 1 and 2.

\section{Discussion}

Our results confirm that in both diabetic and non-diabetic subjects, fructose has less glycaemic effect and induces less insulin secretion than starch. This highlights the potential usefulness of fructose in the diabetic diet (Wolever \& Brand Miller, 1995).
However, it is clear from our results that fructose potentiates postprandial lipaemia in both diabetic and non-diabetic subjects. This is perhaps surprising in view of the evidence, reviewed by Frayn \& Kingman (1995), that the elevation of plasma TAG on high-sucrose or high-carbohydrate diets given for periods ranging from 2 weeks to 6 months is not seen as consistently in diabetic subjects as it is in 


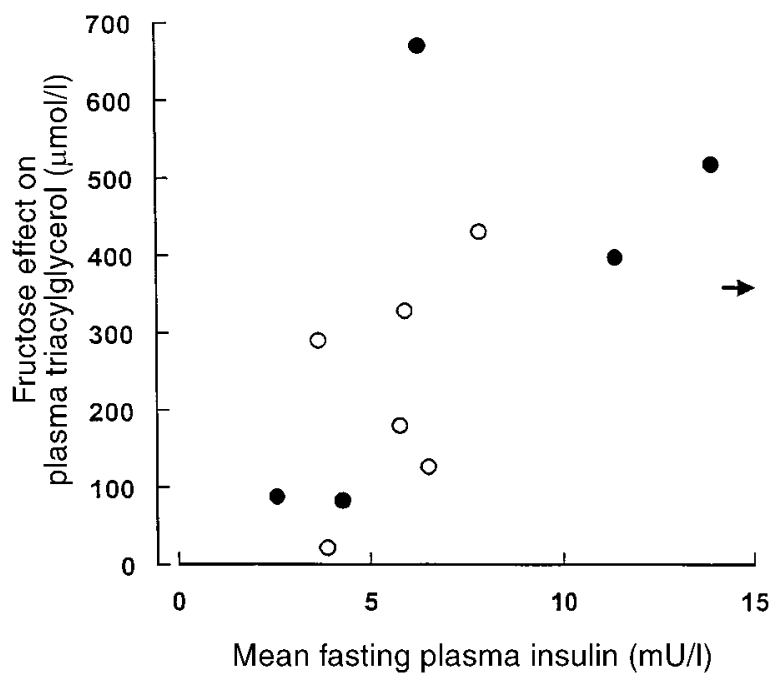

Fig. 5. Relationship between fructose effect on plasma triacylglycerol concentration ( $\mu \mathrm{mol} / /$; postprandial incremental area in fructose study minus that in starch study, divided by $360 \mathrm{~min}$ ) and mean fasting insulin concentration. $(\bigcirc)$, Non-diabetic subjects; $(\bullet)$, diabetic subjects. Each point represents one subject. $\rightarrow$, One additional diabetic subject with a fasting insulin concentration of $31.8 \mathrm{mU} / \mathrm{l}$.

non-diabetic subjects. In the majority of these studies only the fasting plasma TAG concentration has been measured. Measurement of fasting plasma TAG concentration may not be adequate for describing the effect of dietary sugars. Hayford et al. (1979), in a study of formula diets containing high amounts (45 and $65 \%$ of energy) of sucrose or maize syrup (mainly glucose), found that although the effects of these sugars on fasting plasma TAG concentration were not different from each other, the sucrose-rich diet significantly increased the $24 \mathrm{~h}$ integrated plasma TAG profiles compared with the diet containing maize syrup.

The mechanism of potentiation of postprandial lipaemia by fructose has not been clarified. There are suggestions both of increased hepatic secretion of TAG-rich lipoproteins and of impaired TAG clearance (Grant et al. 1994; Jeppesen et al. 1995). Our measurements of post-heparin plasma LPL activity at the end of each study did not show differences between fructose or starch. However, by measuring several related metabolites we have shown some interesting features of the response to fructose. Immediately following the meals, the plasma NEFA concentration decreased in both groups of subjects as the blood glucose and plasma insulin concentrations increased (Fig. 3). Insulin-mediated suppression of NEFA release from adipose tissue is normal after a mixed meal (Coppack et al. 1990). The decline in plasma NEFA concentrations, however, was greater after the fructose meal than after the starch meal, although the insulin response was less. Nuttall et al. (1992) also observed that oral fructose led to suppression of plasma NEFA concentrations to as great a degree as did oral glucose, even though the insulin response to fructose was considerably less. Similarly, a high-fructose diet has been reported to increase the anti-lipolytic effect of insulin in rat adipose tissue (Rizkalla et al. 1992). This could be interpreted to mean that fructose induced an acute increase in the sensitivity of lipolysis to suppression by insulin. A high-fructose diet (20\% of carbohydrate energy) for 4 weeks has been shown to produce a $34 \%$ increase in the sensitivity of glucose metabolism to insulin in subjects with NIDDM (Koivisto \& Yki-Järvinen, 1993). Interestingly, the plasma NEFA concentrations were reversed later in the postprandial period, with greater NEFA concentrations following the fructose meal, at just the same time that plasma TAG concentrations were increased following this meal. This might suggest that plasma NEFA dynamics underlie the changes in TAG metabolism induced by fructose, perhaps by regulation of hepatic TAG secretion rate.

Some studies have indicated that certain group of subjects are more prone to the TAG-elevating effect of dietary sugars than others. These groups include the elderly, sedentary subjects, those with established coronary artery disease (Palumbo et al. 1977), males (Reiser et al. 1981), and hyperinsulinaemic or carbohydrate-sensitive subjects (Reiser et al. 1981; Hallfrisch et al. 1983). Our finding of a relationship between the fasting insulin concentration and the potentiation of postprandial lipaemia by fructose adds weight to the idea of insulin resistance as a factor predisposing to this effect. Since insulin resistance is an important feature of NIDDM, it is perhaps not surprising that the acute effect of fructose is clearly seen in that group. The chronic effects of a high-sucrose or high-carbohydrate diet may well be different from the acute effects of a fructose load.

It is important to put these studies into perspective in relation to normal meals. The dose of fructose used $(0.75 \mathrm{~g} /$ $\mathrm{kg}$ body weight) is large compared with the average daily intake of this sugar, which in different surveys in North America has been estimated to be from $19 \mathrm{~g} / \mathrm{d}$ per person (Gibney et al. 1995) to $37 \mathrm{~g} / \mathrm{d}$ per person (Glinsmann \& Park, 1995). The dose-response relationship for the effect of fructose on postprandial lipaemia has not been adequately tested, although for potentiation of the glycaemic response there is a marked effect after $50 \mathrm{~g}$ fructose, with a much lesser effect of $35 \mathrm{~g}$ (Nuttall et al. 1992). Further work, both on the acute responses to differing amounts of fructose, and on the longer-term effects of high-sucrose or high-carbohydrate diets, is clearly needed.

\section{Acknowledgements}

We thank the Sugar Bureau for a donation towards support of these studies, and Fournier Pharmaceuticals for the Fournier Lipidology award to Dr Abraha. We thank the volunteers and other members of the Oxford Lipid Metabolism Group for help with the studies.

\section{References}

Abraha A, Humphreys SM \& Frayn KN (1996) Acute augmentation of postprandial lipaemia by fructose. Proceedings of the Nutrition Society 56, 171A.

Austin MA (1989) Plasma triglyceride as a risk factor for coronary heart disease. The epidemiologic evidence and beyond. American Journal of Epidemiology 129, 249-259.

Coppack SW, Fisher RM, Gibbons GF, Humphreys SM, McDonough MJ, Potts JL \& Frayn KN (1990) Postprandial substrate deposition in human forearm and adipose tissues in vivo. Clinical Science 79, 339-348. 
Frayn KN \& Kingman SM (1995) Dietary sugars and lipid metabolism in humans. American Journal of Clinical Nutrition Suppl., 62, 250S-263S.

Gibney M, Sigman-Grant M, Stanton JLJ \& Keast DR (1995) Consumption of sugars. American Journal of Clinical Nutrition 62, Suppl., 178S-194S.

Glinsmann WH \& Park YK (1995) Perspective on the 1986 Food and Drug Administration assessment of the safety of carbohydrate sweeteners: uniform definitions and recommendations for future assessments. American Journal of Clinical Nutrition 62, Suppl., 161S-169S.

Grant KI, Marais MP \& Dhansay MA (1994) Sucrose in a lipidrich meal amplifies the postprandial excursion of serum and lipoprotein triglyceride and cholesterol concentrations by decreasing triglyceride clearance. American Journal of Clinical Nutrition 59, 853-860.

Hallfrisch J, Reiser S \& Prather ES (1983) Blood lipid distribution of hyperinsulinemic men consuming three levels of fructose. American Journal of Clinical Nutrition 37, 740748.

Hayford JT, Danney MM, Wiebe D, Roberts S \& Thompson RG (1979) Triglyceride integrated concentration: Effect of variation of source and amount of dietary carbohydrate. American Journal of Clinical Nutrition 32, 1670-1678.

Humphreys SM, Fisher RM \& Frayn KN (1990) Micro-method for measurement of sub-nanomole amounts of triacylglycerol. Annals of Clinical Biochemistry 27, 597-598.

Jeppesen J, Chen Y-DI, Zhou M-Y, Schaaf P, Coulston A \& Reaven GM (1995) Postprandial triglyceride and retinyl ester responses to oral fat: effects of fructose. American Journal of Clinical Nutrition 61, 787-791.

Koivisto VA \& Yki-Järvinen H (1993) Fructose and insulin sensitivity in patients with type 2 diabetes. Journal of Internal Medicine 233, 145-153.

MacDonald I \& Braithwaite DM (1964) The influence of dietary carbohydrates on the lipid pattern in serum and in adipose tissue. Clinical Science 27, 23-30.

Moorhouse JA \& Kark RM (1957) Fructose and diabetes. American Journal of Medicine 23, 46-58.

Nilsson-Ehle P \& Schotz MC (1976) A stable, radioactive substrate emulsion for assay of lipoprotein lipase. Journal of Lipid Research 17, 536-541.

Nuttall FQ, Gannon MC, Burmeister LA, Lane JT \& Pyzdrowski KL (1992) The metabolic response to various doses of fructose in type II diabetic subjects. Metabolism 41, 510-517.

Palumbo PJ, Briones ER, Nelson RA \& Kottke BA (1977) Sucrose sensitivity of patients with coronary-artery disease. American Journal of Clinical Nutrition 30, 394-401.

Reiser S, Bickard MC, Hallfrisch J, Michaelis OE \& Prather ES (1981) Blood lipids and their distribution in lipoproteins in hyperinsulinemic subjects fed three different levels of sucrose. Journal of Nutrition 111, 1045-1057.

Rizkalla SW, Luo J, Guilhem I, Boillot J, Bruzzo F, Chevalier A \& Slama G (1992) Comparative effects of 6 week fructose, dextrose and starch feeding on fat-cell lipolysis in normal rats: effects of isoproterenol, theophylline and insulin. Molecular and Cellular Biochemistry 109, 127-132.

Ruderman NB, Jones AL, Krauss RM \& Shafrir E (1971) A biochemical and morphologic study of very low density lipoproteins in carbohydrate-induced hypertriglyceridemia. Journal of Clinical Investigation 50, 1355-1368.

Wolever TMS \& Brand Miller J (1995) Sugars and blood glucose control. American Journal of Clinical Nutrition 62, Suppl., 212S-227S. 